\title{
The Influence of Oxide Color on the Surface Characteristics of Zirconium Alloy ZrNb7 (wt\%) After Different Heat Treatments
}

\author{
Mike Mosbacher ${ }^{1} \cdot$ Markus Holzinger $^{1} \cdot$ Mathias Galetz $^{2} \cdot$ Uwe Glatzel $^{1}$
}

Received: 15 November 2020 / Revised: 14 March 2021 / Accepted: 17 March 2021 /

Published online: 27 April 2021

(c) The Author(s) 2021

\begin{abstract}
Oxidized zirconium alloys can appear as black, white and all gray shades depending on the heat treatment process. The black color results from a high amount of oxygen vacancies in non-stoichiometric zirconia $\left(\mathrm{ZrO}_{2-x}\right)$ that effectively reduces the band gap of the material. In this work we compare the surface properties of black and white zirconia on $\mathrm{ZrNb} 7$ substrate. An oxidation in air at $600{ }^{\circ} \mathrm{C}$ for $1 \mathrm{~h}$ results in a dark-gray oxide with only a few micro cracks. Oxidation at low oxygen partial pressure at $600{ }^{\circ} \mathrm{C}$ for $8 \mathrm{~h}\left(p_{\mathrm{O} 2}=10^{-19} \mathrm{~Pa}\right)$ generates a dense, totally black oxide scale. A three step heat treatment process, that was introduced for better coating adhesion, results in a white oxide layer with many micro cracks parallel to the surface. From the results of various microscopy and spectroscopy techniques, we derive a model of the layer formation of zirconia on $\mathrm{ZrNb} 7$ and give reason why black zirconia, and therefore the oxidation at low oxygen partial pressure, is favorable for tribological applications (e.g., artificial joint replacements).
\end{abstract}

Keywords Oxidized zirconium · Oxide color · Oxygen vacancies · Surface properties

\section{Introduction}

Oxidized zirconium alloys (mostly $\mathrm{ZrNb} 2.5$ ) are widely used in joint prostheses such as artificial knee joints because of their favorable properties. Those are the high hardness, the abrasion and corrosion resistance of the oxide scale, the ductility of the metallic substrate and the high biocompatibility of zirconium as metal [1-5]. In

Uwe Glatzel

uwe.glatzel@uni-bayreuth.de

1 Metals and Alloys, University of Bayreuth, Prof.-Rüdiger-Bormann-Str. 1, 95447 Bayreuth, Germany

2 DECHEMA-Forschungsinstitut, Theodor-Heuss-Allee 25, 60486 Frankfurt am Main, Germany 
this work, alloys like $\mathrm{ZrNb} 7$ are oxidized in air between 500 and $700{ }^{\circ} \mathrm{C}$ to generate an oxide scale of about 5-7 $\mu \mathrm{m}$ thickness. This oxide scale is chemically bonded to the substrate via a thin oxygen diffusion zone, as zirconium has the ability to solve up to 30 at $\%$ of oxygen in its lattice at temperatures around $700{ }^{\circ} \mathrm{C}$. This ability is only observed in Ti, Hf and $\mathrm{Zr}$.

Previous works have focused on enlarging the diffusion zone via a solid state reduction [6-8]. During this process, oxygen from the oxide scale diffuses into the metal substrate and thereby reduces the hardness gradient between surface and bulk material. This in return can enhance coating adhesion [6-8].

Depending on the heat treatment, the zirconia scale can turn out black or white, and various gray shades in-between. In literature this effect is related to an oxygen deficiency in the oxide lattice [3, 9-12]. Those oxygen vacancies get occupied by two electrons from the neighboring zirconium to compensate charge in the lattice and therefore form so-called F-centers (or color centers). With an increasing number of these localized electrons, the band gap of zirconia is reduced from $5.1 \mathrm{eV}$ (white oxide) down to $1.5 \mathrm{eV}$ (black oxide) [13]. Durov et al. [11] claim that $10^{17}$ F-centers per cubic centimeter are enough to turn zirconia black.

In this work we investigate the surface of oxidized $\mathrm{ZrNb} 7$ with three different heat treatment routes. A regular oxidation in air, an oxidation at low oxygen partial pressure and a three step heat treatment. The first two produce dark-gray to black oxides and the latter results in a white oxide layer. With the help of different microscopy and spectroscopy techniques, we give an insight in how stoichiometric and non-stoichiometric $\mathrm{Zr}$-oxide layers form and how the color of the oxide is linked with its mechanical properties.

\section{Experimental Procedures}

\section{Materials}

$\mathrm{ZrNb} 7$ (wt \%) rods are cast in an arc melting furnace under argon pressure of $5 \cdot 10^{4} \mathrm{~Pa}$ (500 mbar) from elemental zirconium (99.2\% purity) and niobium $(99.9 \%$ purity). To ensure high homogeneity, the melted ingots are remelted five times before a sixth remelting step to form a rod with a diameter of $10 \mathrm{~mm}$ and a length of about $100 \mathrm{~mm}$. The specimens are analyzed in a micro X-ray fluorescence analyzer ( $\mu$-XRF, Orbis PC, EDAX) to ensure the right chemical composition and high homogeneity before heat treatments.

\section{Heat Treatments of ZrNb7}

The $\mathrm{ZrNb} 7$ samples are subject to three different heat treatment processes: an oxidation in air, a three step heat treatment and a single step oxidation at low oxygen partial pressure. All following scale and layer thicknesses were measured in SEM micrographs of sample cross sections with 100 thickness measurements per micrograph at three random areas of the sample. 


\section{Oxidation in Air}

The samples are oxidized in air at $600{ }^{\circ} \mathrm{C}$ for $1 \mathrm{~h}$, generating an oxide scale thickness of $6 \mu \mathrm{m}$ and an oxygen diffusion zone of $4 \mu \mathrm{m}$. The oxide appears dark-gray.

\section{Three Step Heat Treatment}

After an initial oxidation in air at $600{ }^{\circ} \mathrm{C}$ for $1 \mathrm{~h}$, the samples are deoxidized at $700{ }^{\circ} \mathrm{C}$ for $20 \mathrm{~h}$ in sealed quartz glass tubes, that are evacuated to a pressure of $4 \cdot 10^{3} \mathrm{~Pa}$. During this step the oxide scale is fully dissolved and oxygen diffuses into the metal substrate, generating a pronounced oxygen diffusion zone. In a final step, samples are oxidized again at $600{ }^{\circ} \mathrm{C}$ for $1 \mathrm{~h}$ to generate the desired ceramic oxide scale while retaining a large fraction of the diffusion zone. This heat treatment process leads to an oxide scale thickness of $13 \mu \mathrm{m}$ and an oxygen diffusion zone of $27 \mu \mathrm{m}$. The oxide appears white. For detailed information on the three step heat treatment process see [8].

\section{Oxidation at Low Oxygen Partial Pressure}

In this heat treatment process samples are oxidized in a special furnace that allows for very low oxygen partial pressures (see details of the furnace in [14]). The oxidation at $600{ }^{\circ} \mathrm{C}\left(\mathrm{p}_{\mathrm{O} 2}=10^{-19} \mathrm{~Pa}\right)$ for $8 \mathrm{~h}$ generates an oxide scale thickness of $7 \mu \mathrm{m}$ and a diffusion zone of $11 \mu \mathrm{m}$. The oxide appears black.

See Fig. 1, for a comparison of the three different heat treatment processes and their effect on the microstructural properties of the surface near layers.

\section{Analysis Methods}

For microstructural analysis of the surface near layers, cross sections of the specimens are prepared using SiC paper up to grit 2000, which are then polished with a mixture of $2 / 3$ colloidal silica suspension and $1 / 3$ hydrogen peroxide solution.

The cross sections are investigated using an optical microscope (Axioplan 2, Zeiss) as well as a scanning electron microscope (SEM, 1540 EsB Cross Beam, Zeiss). The SEM is equipped with an energy-dispersive X-ray spectroscopy detector (EDS, Thermo Fisher Scientific), which is used for chemical analysis.

The oxide surfaces are analyzed using SEM, EDS, X-ray diffractometry (XRD, D8 ADVANCE, Bruker), X-ray photoelectron spectroscopy (XPS, VersaProbe III, Physical Electronics) and Raman spectroscopy (alpha 300 RA +, WITec). 


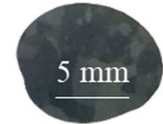

grey

(a) oxidation in air

$600^{\circ} \mathrm{C}, 1 \mathrm{~h}$

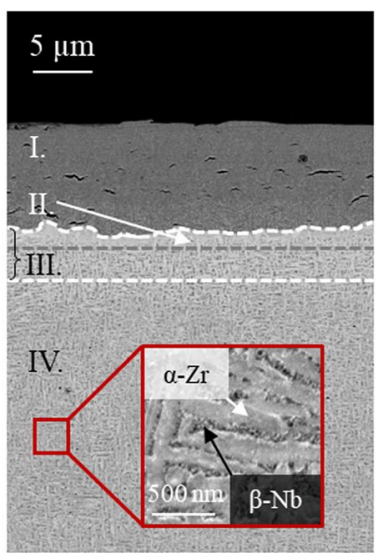

white

(b) three step heat treatment

1. $600^{\circ} \mathrm{C}, 1 \mathrm{~h}$

2. $700^{\circ} \mathrm{C}, 20 \mathrm{~h}$ (in vacuum)

3. $600^{\circ} \mathrm{C}, 1 \mathrm{~h}$

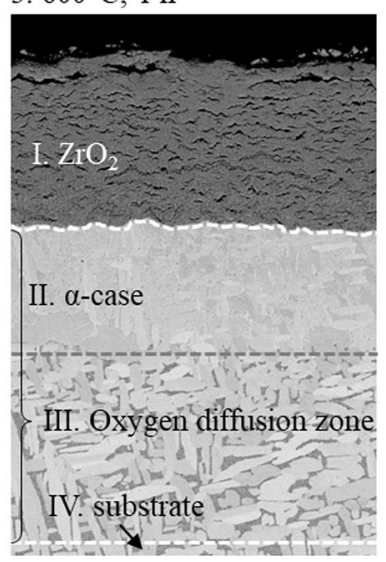

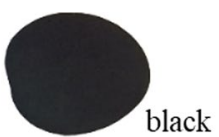

(c) oxidation at low $\mathrm{p}_{\mathrm{O}_{2}}$

$600^{\circ} \mathrm{C}, 8 \mathrm{~h}\left(\mathrm{p}_{\mathrm{O}_{2}}=10^{-19} \mathrm{~Pa}\right)$

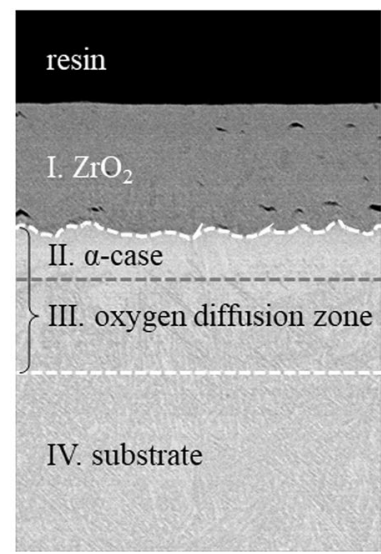

Fig. 1 Oxide color and microstructural features of the surface near layers of $\mathrm{ZrNb} 7$ with three different heat treatment routes. The characteristic layer formation is: $\mathrm{I}: \mathrm{ZrO}_{2}$, II: $\alpha$-case, III: oxygen diffusion zone, IV: substrate. The $\alpha$-case is part of the oxygen diffusion zone and its boundary is indicated by a dashed gray line

\section{Results}

\section{Microstructure of the Oxide and the Surface Near Layers}

The three different heat treatment routes lead to different morphologies in the oxide layers, as shown in Fig. 1. The basic layer formation is the same in all three process routes: the oxide scale is chemically bonded to the substrate by an oxygen diffusion zone. Within this layer a so called $\alpha$-case forms with $(\alpha-Z r)$ as the main phase with very thin $(\beta-\mathrm{Zr}, \mathrm{Nb})$ channels in between. As the $(\beta-\mathrm{Zr}, \mathrm{Nb})$ channels are very small with $10-20 \mathrm{~nm}$, the $\alpha$-case appears as a single phase region at medium magnifications. The thickness of the oxygen diffusion zone is not visible in SEM, but can be quantified using either EDS or hardness measurements. Data of EDS measurements can be found in our earlier work [8]. Data of our hardness measurements will be published elsewhere together with the results of the tribological experiments. The substrate shows a two phase morphology with $\alpha$-plates and $\beta$-channels with thickness of 10-20 $\mathrm{nm}$ in between (see inset in Fig. 1a).

Samples that are oxidized in air at $600{ }^{\circ} \mathrm{C}$ for $1 \mathrm{~h}$ show a dense, dark-gray oxide layer of $6 \mu \mathrm{m}$ followed by a small oxygen diffusion zone of $4 \mu \mathrm{m}$ (Fig. 1a).

The three step heat treatment process results in a white oxide layer with a thickness of $13 \mu \mathrm{m}$ that is penetrated by fine micro cracks parallel to the surface, as shown in Fig. 1b. The oxygen diffusion zone reaches $27 \mu \mathrm{m}$ deep into the substrate, 
which is coarsened by the long annealing time of $20 \mathrm{~h}$ at $700{ }^{\circ} \mathrm{C}$ during the deoxidation step.

Samples that are oxidized at low oxygen partial pressure show a morphology that resembles a combination of the above described two process routes (Fig. 1c). These specimens show a dense, black oxide layer of $7 \mu \mathrm{m}$ that is followed by a pronounced oxygen diffusion zone with a thickness of $11 \mu \mathrm{m}$.

In the following, we focus on the white oxide layer of the three step heat treated samples and the black oxide layer of the samples, that were oxidized at low oxygen partial pressure. They will be denoted as white and black sample hereafter.

The oxide surface of the three step heat treated sample is very uneven with some spalled off regions, see Fig. 1b. The top view on the oxide surface confirms this and also exhibits charging in SEM, as shown in Fig. 2a. This is an evidence for poor electric conductivity. The black oxide, exhibits no charging at all and shows an even surface with no spalling or cracks. This supports the hypothesis that black zirconia contains large amounts of oxygen vacancies increasing the conductivity of the ceramic surface. Additionally EDS analysis at three different regions of the samples show a slight variation in oxygen content of 0.5 at $\%$, which supports this theory as well.

\section{X-ray Diffraction (XRD)}

Due to thermally induced oxygen vacancies, zirconia exhibits three different modifications: the monoclinic $(m)$ phase up to $1170{ }^{\circ} \mathrm{C}$, the tetragonal $(t)$ phase up to $2370{ }^{\circ} \mathrm{C}$ and the cubic $(c)$ phase above $2370{ }^{\circ} \mathrm{C}$ [15]. XRD measurements show, that irrespective of the heat treatment, all investigated samples show mainly monoclinic $\mathrm{ZrO}_{2}$, see Fig. 3. The main difference of black and white zirconia in XRD is the pronounced $\alpha-\mathrm{Zr}$ peaks, that show up in the black sample (additionally marked with vertical, black line). The reason is X-ray photons penetrating the metallic substrate underneath the oxide layer. The oxide scale of the black sample is about $7 \mu \mathrm{m}$ thick,

(a) white

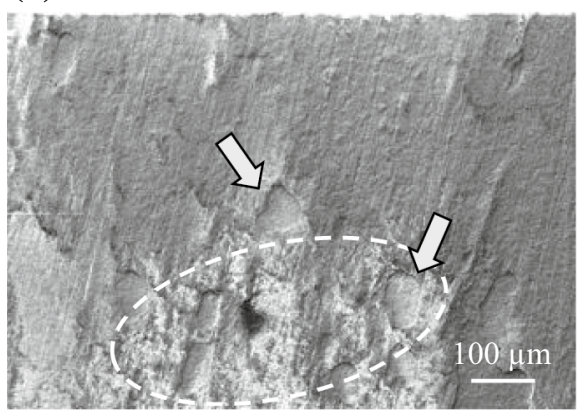

(b) black

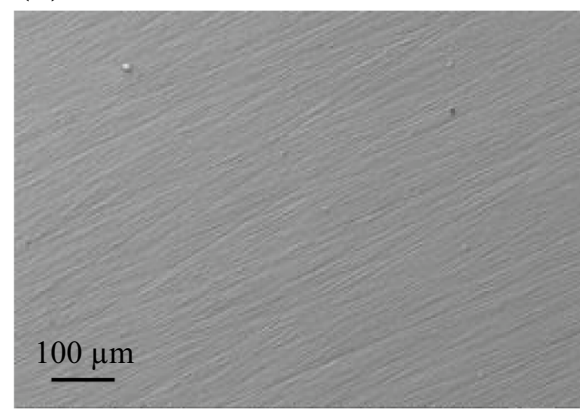

Fig. 2 SEM micrographs of the oxide surfaces. a The white oxide of the 3-step heat treatment shows charging artifacts (indicated by dashed white line) and spalled regions (indicated by white arrows). B The black oxide (oxidation at low $p_{02}$ ) has a lower oxygen content and shows no signs for charging effects. This leads to the conclusion that the black oxide features a better conductivity than the white surface 
Fig. 3 XRD measurements of white and black zirconia layers on top of $\mathrm{ZrNb} 7$ after different heat treatments. The black sample shows pronounced metallic $\alpha-\mathrm{Zr}$ peaks that are additionally marked by a black vertical line

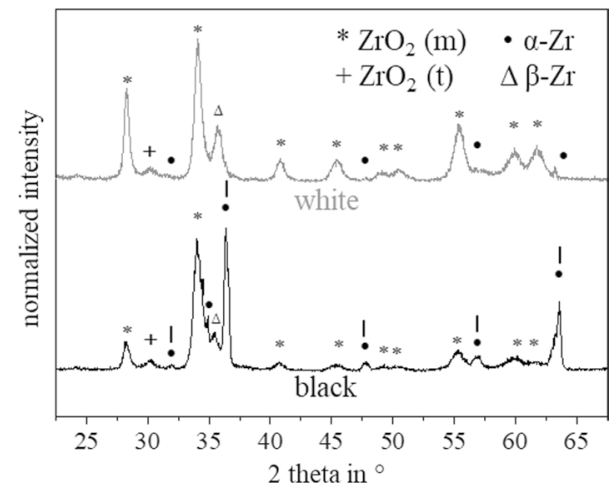

while the white oxide scale is $13 \mu \mathrm{m}$. The penetration depth of $\mathrm{Cu} \mathrm{K} \alpha$ photons is around $10 \mu \mathrm{m}$ at $\theta=30^{\circ}$ for $\mathrm{ZrO}_{2}$ with an absorption of $90 \%$. Therefore X-rays can reach the metallic surface of the black sample, but not that of the white sample.

The pronounced $\beta-\mathrm{Zr}$ peak in white zirconia probably results from residual $\beta-\mathrm{Zr}$ channels in the zirconia layer. During the third heat treatment step the sample is oxidized again and parts of the $\alpha$-case is turned into zirconium oxide. The small $\beta$-channels have niobium concentrations of more than 40 at $\%$ and can therefore not be oxidized at the existing oxygen partial pressure at the oxide/metal interface.

\section{X-ray Photoelectron Spectroscopy (XPS)}

The outermost surface of the black and white sample is investigated using XPS, as photoelectrons originate from a depth of $2-5 \mathrm{~nm}$. Oxygen vacancies should be clearly visible in XPS both in Zr3d-peaks and in O1s-peaks. Sinhamahapatra et al. [13] show a shift of the Zr3d-peak to lower binding energies in black zirconia which correlates to $\mathrm{Zr}^{(4-x)+}$ ions. These $\mathrm{Zr}^{(4-x)+}$ ions generate a shoulder of the $\mathrm{Zr}^{4+}$ peak at around $180 \mathrm{eV}$. The O1s-peak features a higher fraction of unbound oxygen. These results are an indicator for oxygen vacancies. However, our XPS measurements cannot confirm these findings. Both Zr3d- and O1s-peaks are identical in black and white zirconia, see Fig. 4.

To gain information of volumes further away from the original surface, argon sputtering is used to remove the outermost layers. After an initial appearance of a peak shoulder at $180 \mathrm{eV}(\mathrm{Zr} 3 \mathrm{~d})$ and removal of surficial oxygen in $\mathrm{O} 1 \mathrm{~s}$, both samples show no alteration of $\mathrm{Zr}$ - and O-peaks in deeper layers, see Fig. 5. The numbers shown at the peaks are the respective sputter cycle, after which the spectrum has been obtained. The shoulder of the $\mathrm{Zr} 3 \mathrm{~d}$-peak at around $180 \mathrm{eV}$ is due to sputter damage and is overlaying the information to be shown: potential $\mathrm{Zr}^{(4-x)+}$ ions in the lattice. This degradation of $\mathrm{ZrO}_{2}$ into suboxides under argon bombardment is well reported in the literature (i.e., Iwamoto et. al [16]) and is visible on the surface of the white oxide, as a dark spot in the sputtered region, which is marked by a white arrow in Fig. 5a. 

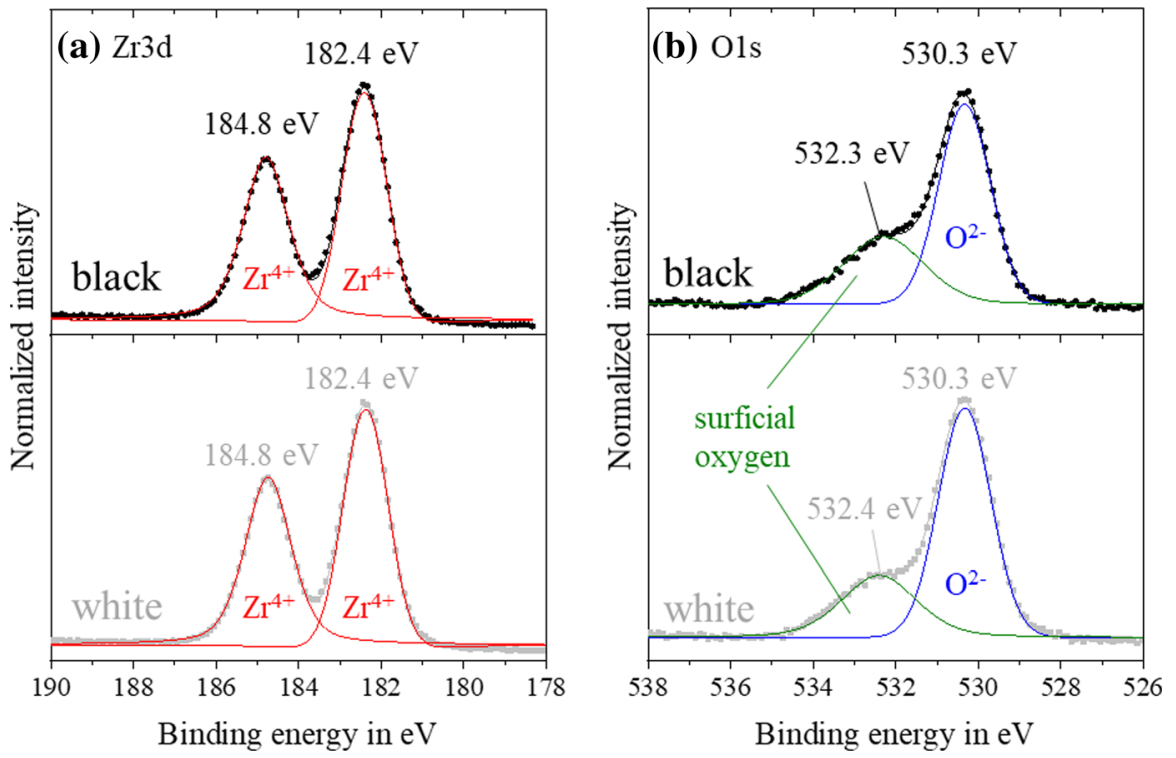

Fig. 4 XPS measurements of $\mathbf{a} \mathrm{Zr} 3 \mathrm{~d}$ and $\mathbf{b} \mathrm{O} 1 \mathrm{~s}$ of black and white samples
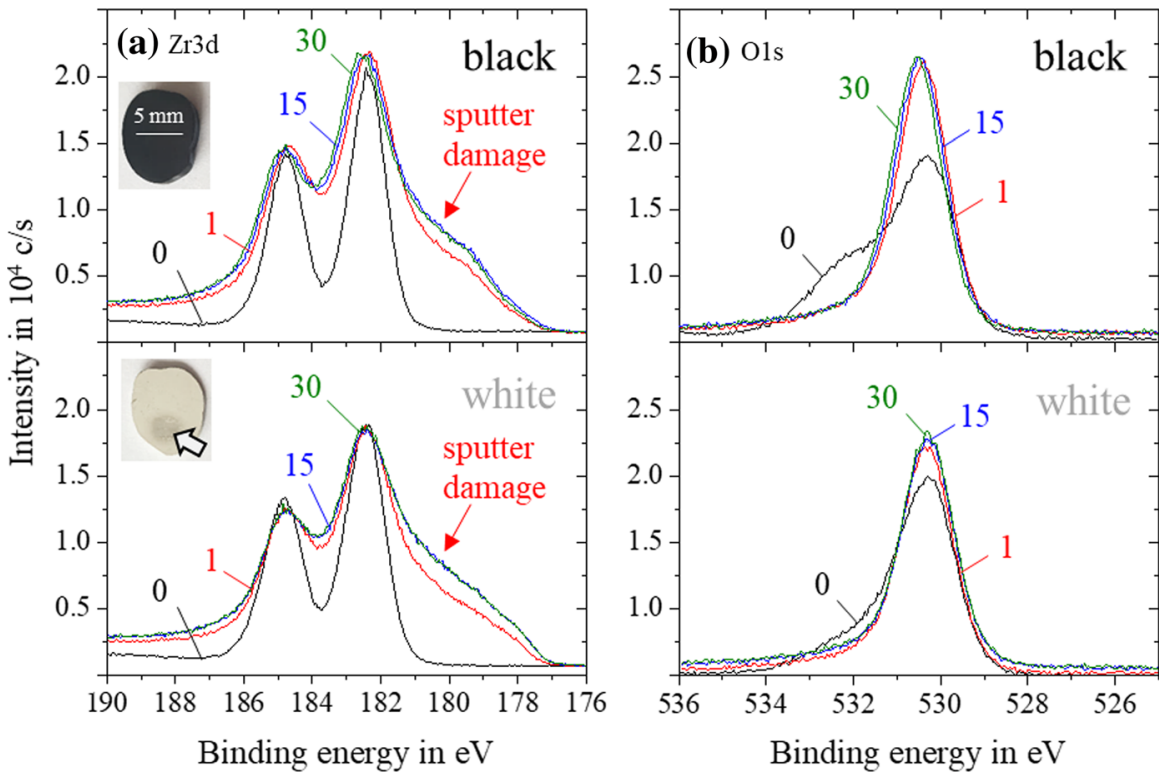

Fig. 5 Zr3d-peaks (a) and O1s-peaks (b) after removal of outermost layers by argon sputtering 


\section{Raman Spectroscopy}

Raman spectroscopy is very sensitive to lattice distortions, such as crystallinity, doping and vacancies. Raman spectra of black and white oxide layers are displayed in Fig. 6. The former shows wider peaks, a worse signal-to-noise ratio and some peaks disappear in the background. These features are marked with a star (*). The results are in very good agreement with the literature [17, 18]. Leto et al. [17] have investigated a sample made out of Oxinium ${ }^{\mathrm{TM}}$ (oxidized $\mathrm{ZrNb} 2.5$ alloy-black oxide) and a monoclinic $\mathrm{ZrO}_{2}$ single crystal. The spectrum of the black sample of this work shows good agreement with the Oxinium ${ }^{\mathrm{TM}}$ sample, while the white sample resembles the results of the monoclinic $\mathrm{ZrO}_{2}$.

The depth of information in Raman spectroscopy is mainly dependent on absorption or transmission of the examined material. For optically transparent or white materials the depth of information equals the depth of resolution of the confocal microscope. For a frequency doubled Nd:YAG laser $(\lambda=532 \mathrm{~nm})$ and an aperture angle of $33^{\circ}$ the depth of resolution equals $1.6 \mu \mathrm{m}$. This correlates to the origin of the inelastic scattered photons of the white oxide. For the black sample however, all visible light is absorbed, and therefore, no precise prediction for the depth of information can be given. It can be stated however, that the information should arise from a depth closer to the surface, than in the white oxide.

\section{Discussion}

By combining all results of the different experiments, we derive a model of the surface near layers of white and black zirconia. Figure 7 summarizes all results from the different investigation methods including the respective depth of information (DOI).

The XPS results suggest a stoichiometric $\mathrm{ZrO}_{2}$ layer as the outermost layer of the black oxide that is only a few nanometers thin and therefore could be optically transparent. The laser in Raman spectroscopy will pass through this transparent

Fig. 6 Raman spectra of black and white zirconia. The most pronounced differences are indicated by a star (*)

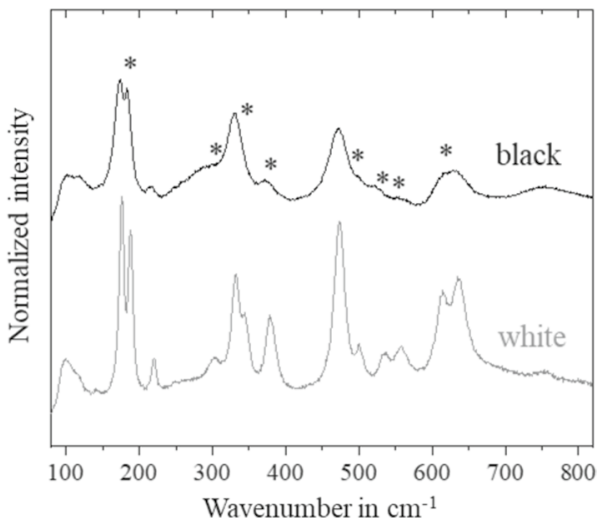




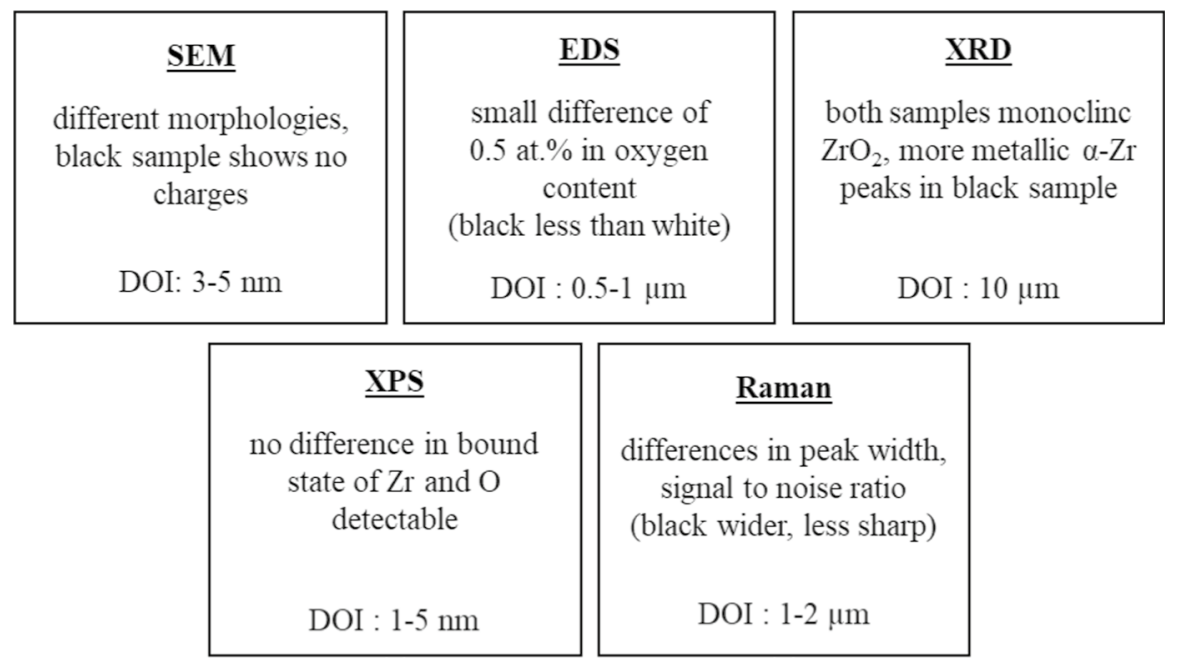

Fig. 7 Summary of the results from different investigation methods as well as the respective depth of information (DOI)

layer and the information comes from the non-stoichiometric oxide layer below, which has an increasingly high oxygen vacancy concentration.

With this knowledge, we propose a schematic layer sequence can be created, see Fig. 8. In the case of black oxide (Fig. 8a), only a few $\mathrm{nm}(\geq 5 \mathrm{~nm})$ thin $\mathrm{ZrO}_{2}$ layer is followed by a sub-stoichiometric $\mathrm{ZrO}_{2-\mathrm{x}}$ layer, which is decisive for the color and the properties of the oxide. It has a very high concentration of oxygen vacancies (indicated by $2 \mathrm{e}^{-}$due to the fact that the missing ion is charged twice negative), which probably act as elastic buffers and reduce the internal stresses in the oxide, as the F-centers increase the fraction of metallic bonds in the ceramic. This could increase stress tolerance in the oxide scale and therefore lead to a denser and less cracked oxide layer. The $\mathrm{ZrO}_{2-x}$ layer is followed by the oxygen diffusion zone, in which the oxygen content in the metal gradually drops from just under 30 at $\%$ to substrate level.

Figure $8 \mathrm{~b}$ shows the white oxide, which has a pronounced stoichiometric $\mathrm{ZrO}_{2}$ layer of a few $\mu \mathrm{m}$ thickness on the surface. Stoichiometric (white) $\mathrm{ZrO}_{2}$ has a Pilling Bedworth value (ratio of the molar volumes of a metal oxide and its corresponding metal) of 1.57 . This indicates that strong compressive stresses arise in the oxide during growth, which results in an oxide layer that is severely cracked (indicated in Fig. 8b). It can be assumed that a sub-stoichiometric $\mathrm{ZrO}_{2-x}$ layer can be found near the oxide/metal interface as well, since oxygen diffuses into the metallic substrate at all times during heat treatments above $500{ }^{\circ} \mathrm{C}$.

As the oxidation at low oxygen partial pressure limits the amount of oxygen available in the surrounding atmosphere, large amounts of oxygen can diffuse into the substrate at the same time as the oxide scale is formed. This generates the largest amount of sub-stoichiometric $\mathrm{ZrO}_{2-x}$ in the oxide scale of all investigated 
(a)

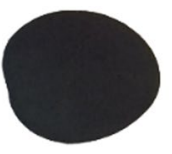

few

$\mathrm{nm}$

some

$\mu \mathrm{m}$

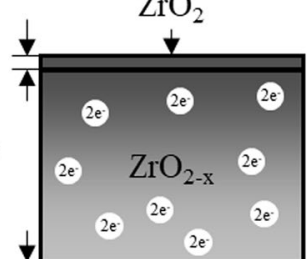

$\mathrm{Zr}(\mathrm{O})$

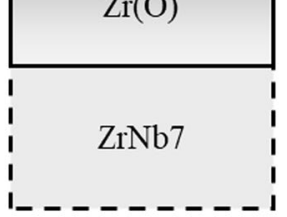

(b)

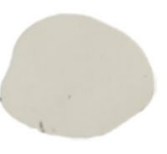

$\mathrm{c}_{\mathrm{O}_{2}}$ in at. $\%$

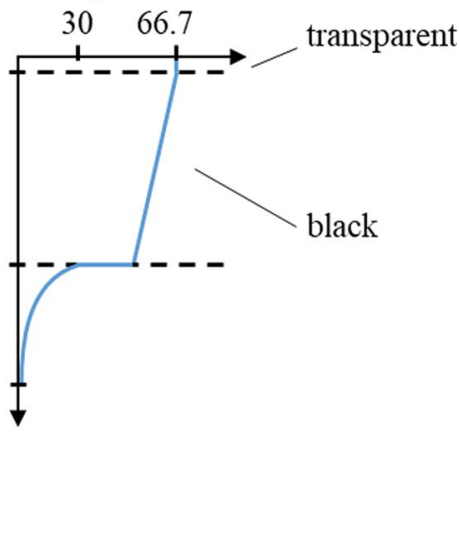

$\mathrm{c}_{\mathrm{O}_{2}}$ in at. $\%$

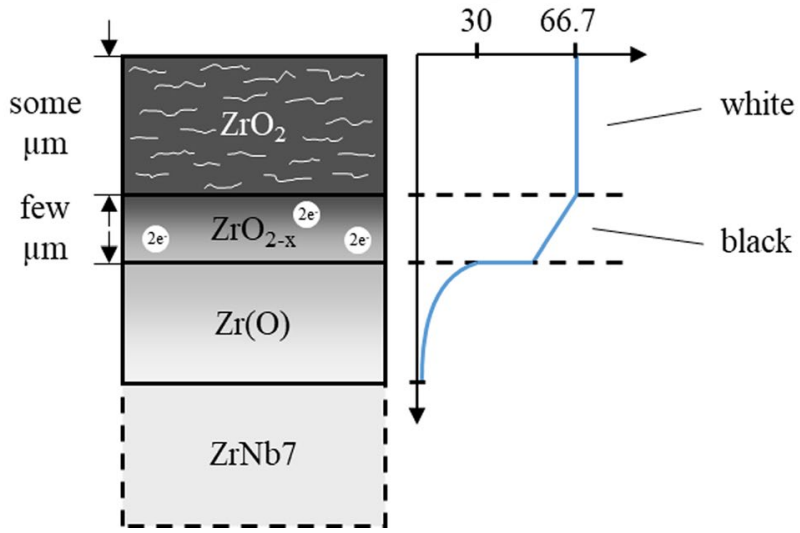

Fig. 8 Schematic model of the surface near layers of oxidized $\mathrm{ZrNb} 7$ : a black oxide: oxygen vacancies (indicated by $2 \mathrm{e}^{-}$due to the fact that the missing ion is charged twice negative) reduce inner stresses and lead to a dense and protective oxide layer; $\mathbf{b}$ white oxide: lots of micro cracks (indicated by white lines) in the outermost layer lead to spalling and non-protective outer oxide scales

specimens, which can be visibly recognized, as those samples exhibit the darkest black color. The oxidation in air usually results in dark-grey oxide scales and therefore in less oxygen vacancies.

\section{Conclusion}

Our investigations clearly show why white oxide layers on top of zirconium alloys should be avoided at all times, especially when used in tribological applications. The black color is an indicator for protective oxide scales with good mechanical and 
tribological properties that is easily recognizable. The key to these favorable properties lies in the high amount of F-centers, that are generated during the heat treatment process with low oxygen partial pressure.

Funding Open Access funding enabled and organized by Projekt DEAL.

Open Access This article is licensed under a Creative Commons Attribution 4.0 International License, which permits use, sharing, adaptation, distribution and reproduction in any medium or format, as long as you give appropriate credit to the original author(s) and the source, provide a link to the Creative Commons licence, and indicate if changes were made. The images or other third party material in this article are included in the article's Creative Commons licence, unless indicated otherwise in a credit line to the material. If material is not included in the article's Creative Commons licence and your intended use is not permitted by statutory regulation or exceeds the permitted use, you will need to obtain permission directly from the copyright holder. To view a copy of this licence, visit http://creativecommons.org/licen ses/by/4.0/.

\section{References}

1. J.A. Davidson, C.M. Asgian, A.K. Mishra, P. Kovacs, Zirconia (Zr02)-Coated Zirconium-2.5Nb Alloy for Prosthetic Knee Bearing Applications, Bioceramics. 5 (1992) 389-401.

2. G. Hunter, W.M. Jones, M. Spector, Oxidized zirconium, in: J. Bellemans, M.D. Ries, J.M.K. Victor (Eds.), Total Knee Arthroplast. A Guid. to Get Better Perform., Springer Berlin Heidelberg, Berlin, Heidelberg, 2005: pp. 370-377. https://doi.org/10.1007/3-540-27658-0_59.

3. L.W. Hobbs, V.B. Rosen, S.P. Mangin, M. Treska, G. Hunter, Oxidation microstructures and interfaces in the oxidized zirconium knee, Int. J. Appl. Ceram. Technol. 2 (2005) 221-246. https://doi.org/10.1111/j. 1744-7402.2005.02025.x.

4. M. Spector, M.D. Ries, R.B. Bourne, W.S. Sauer, M. Long, G. Hunter, Wear performance of ultra-high molecular weight polyethylene, on oxidized zirconium total knee femoral components, J. Bone Jt. Surg. - Ser. A. 83 (2001) 80-86. https://doi.org/10.2106/00004623-200100022-00004.

5. M.C. Galetz, E.W. Fleischmann, C.H. Konrad, A. Schuetz, U. Glatzel, Abrasion resistance of oxidized zirconium in comparison with CoCrMo and titanium nitride coatings for artificial knee joints, J. Biomed. Mater. Res. - Part B Appl. Biomater. 93 (2010) 244-251. https://doi.org/10.1002/jbm.b.31581.

6. V. Pawar, C. Weaver, S. Jani, Physical characterization of a new composition of oxidized zirconium-2.5 wt $\%$ niobium produced using a two step process for biomedical applications, Appl. Surf. Sci. 257 (2011) 6118-6124. https://doi.org/10.1016/j.apsusc.2011.02.014.

7. M. Reif, F. Scherm, M.C. Galetz, U. Glatzel, An enhanced three-step oxidation process to improve oxide adhesion on zirconium alloys, Oxid. Met. 82 (2014) 99-112. https://doi.org/10.1007/ s11085-014-9479-2.

8. M. Mosbacher, F. Scherm, U. Glatzel, Oxygen diffusion kinetics of an advanced three step heat treatment for zirconium alloy ZrNb7, Surf. Coat. Technol. 339 (2018) 139-146. https://doi.org/10.1016/j.surfcoat. 2018.02.015.

9. H.G. Kim, I.H. Kim, B.K. Choi, J.Y. Park, A study of the breakaway oxidation behavior of zirconium cladding materials, J. Nucl. Mater. 418 (2011) 186-197. https://doi.org/10.1016/j.jnucmat.2011.06.039.

10. D.L. Douglass, C. Wagner, The Oxidation of Oxygen-Deficient Zirconia and Its Relationship to the Oxidation of Zirconium, J. Electrochem. Soc. 113 (1966) 671-676. https://doi.org/10.1149/1.2424088.

11. A. V. Durov, Y. V. Naidich, B.D. Kostyuk, Investigation of interaction of metal melts and zirconia, J. Mater. Sci. 40 (2005) 2173-2178. https://doi.org/10.1007/s10853-005-1928-5.

12. K. Koski, J. Ho, P. Juliet, Properties of zirconium oxide thin films deposited by pulsed reactive magnetron sputtering, 121 (1999) 303-312.

13. A. Sinhamahapatra, J.P. Jeon, J. Kang, B. Han, J.S. Yu, Oxygen-Deficient Zirconia (ZrO2-x): A New Material for Solar Light Absorption, Sci. Rep. 6 (2016) 1-8. https://doi.org/10.1038/srep27218.

14. M. Wenderoth, U. Glatzel, R. Völkl, Experimental studies of internal oxidation in a Ni-Zr-Y alloy, in: Thüringer Werkstofftag, Schnapp J.D., Glatzel U., Jandt K.D., Knake H., 2002.

15. H. Salmang, H. Scholze, Keramik, Springer, Berlin, Heidelberg, 2007 ISBN: 978-3-540-49469-0. 
16. N. Iwamoto, Y. Makino, M. Kamai, Characterization of r.f.-sputtered zirconia coatings, Thin Solid Films. 153 (1987) 233-242. https://doi.org/10.1016/0040-6090(87)90185-4.

17. A. Leto, W. Zhu, M. Matsubara, G. Pezzotti, Bioinertness and fracture toughness evaluation of the monoclinic zirconia surface film of Oxinium ${ }^{\mathrm{TM}}$ femoral head by Raman and cathodoluminescence spectroscopy, J. Mech. Behav. Biomed. Mater. 31 (2014) 135-144. https://doi.org/10.1016/j.jmbbm. 2013.10.026.

18. L. Kurpaska, I. Jozwik, J. Jagielski, Study of sub-oxide phases at the metal-oxide interface in oxidized pure zirconium and $\mathrm{Zr}-1.0 \% \mathrm{Nb}$ alloy by using SEM/FIB/EBSD and EDS techniques, J. Nucl. Mater. 476 (2016) 56-62. https://doi.org/10.1016/j.jnucmat.2016.04.038.

Publisher's Note Springer Nature remains neutral with regard to jurisdictional claims in published maps and institutional affiliations. 